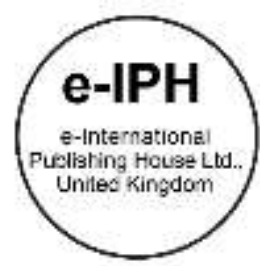

\title{
Helmet Non-invasive Ventilation Therapy: Measurement of comfort behaviour
}

\author{
Norhaini Majid ${ }^{1}$, Roswati Nordin ${ }^{1}$, Norshamatul Aidah Osran ${ }^{1,2}$, Suryanto Suryanto ${ }^{3}$ \\ ${ }^{1}$ Centre for Nursing Studies, Faculty of Health Sciences, Universiti Teknologi MARA (UiTM), Selangor, Malaysia, \\ 2 ILKKM Sultan Azlan Shah, Ipoh, Perak, Malaysia, ${ }^{3}$ School of Nursing, Faculty of Medicine, Universitas Brawijaya, Indonesia
}

majidnorhaini@gmail.com, roswati2809@uitm,norshamatulaidah@gmail.com, suryanto.s@ub.ac.id Tel: +60162384423

\begin{abstract}
Comfort is integral towards tolerance in helmet non-invasive ventilation (NIV) therapy among acute respiratory failure (ARF) patients. This study aims to measure the patients' comfort behaviour level after completion of helmet NIV therapy. It is a quantitative, descriptive, observational study involving 67 ARF patients. Kolcaba's Comfort Behavioural Checklist (CBC) was used, with the highest score of 120. The mean CBC score was 88.54, SD 7.35, indicating moderate comfort level; for Acute Pulmonary Oedema (APO) and non- APO, patients were 89.88, SD 7.25, and 87.08, SD 7.80 respectively. This reflects genuine patients' response towards therapy which is significant for future improvement.
\end{abstract}

Keywords: Helmet Continuous Positive Airway Pressure; CPAP; Kolcaba's Behavioural Checklist; Acute Respiratory Failure

eISSN: 2398-4287@ 2021. The Authors. Published for AMER ABRA cE-Bs by e-International Publishing House, Ltd., UK. This is an open access article under the CC BYNCND license (http://creativecommons.org/licenses/by-nc-nd/4.0/). Peer-review under responsibility of AMER (Association of Malaysian Environment-Behaviour Researchers), ABRA (Association of Behavioural Researchers on Asians/Africans/Arabians) and cE-Bs (Centre for Environment-Behaviour Studies), Faculty of Architecture, Planning \& Surveying, Universiti Teknologi MARA, Malaysia. DOI: https://doi.org/10.21834/ebpj.v6i18.3082

\subsection{Introduction}

Patient comfort is crucial during non-invasive ventilation (NIV) to decrease possible complications leading to endotracheal intubation (Coppadoro et al., 2021). Comfort is a core component in patient-centred care (PCC); a contemporary strategy aims to heighten health care quality. This strategy emphasises patients' active and meaningful involvement in care provision to ensure the service provided optimally fulfils their comfort needs (Mohammed et al., 2016). Based on Kolcaba's Comfort Theory, comfort is crucial to catalyse positive experience towards treatment. Besides, comfort can also be implied as a treatment outcome that reflects the overall level of care. The rapid progression of ventilatory support is an example of quality care improvement. The transition from invasive mechanical ventilation to NIV in Acute Respiratory Failure (ARF) and progression to the better NIV modes have markedly improved clinical outcomes. Various NIV interfaces have been developed: nasal mask, oronasal mask, total face mask, nasal pillows, mouthpiece and helmet (Bello et al., 2013), which indirectly influence the increment in several NIV usage.

Congruous with the PCC concept, the number of comparative studies between NIV interfaces is escalating, inquiring about the most effective and superior interface (Grieco et al., 2020). As a result, Helmet NIV turns to be one of the preferred latest NIV interfaces, considering the abundance of positive outcomes: improved oxygenation (Pisani et al., 2015), reduced work of breathing (WOB), more comfort and better tolerance (Coppadoro et al., 2021; Pisani et al., 2015; Tiru et al., 2017), ease of oral intake and reduce the rate for endotracheal intubation (Grieco et al., 2021), which collectively reduce mortality rate and reduce the length of hospital stay.

Despite helmet NIV's superiority over other interfaces, therapy intolerance is a typical response demonstrated by helmet recipients.

eISSN: 2398-4287@ 2021. The Authors. Published for AMER ABRA cE-Bs by e-International Publishing House, Ltd., UK. This is an open access article under the CC BYNCND license (http://creativecommons.org/licenses/by-nc-nd/4.0/). Peer-review under responsibility of AMER (Association of Malaysian Environment-Behaviour Researchers), ABRA (Association of Behavioural Researchers on Asians/Africans/Arabians) and cE-Bs (Centre for Environment-Behaviour Studies), Faculty of Architecture, Planning \& Surveying, Universiti Teknologi MARA, Malaysia.

DOI: https://doi.org/10.21834/ebpj.v6i18.3082 
Based on a comprehensive review of randomised trials by Liu et al. (2020) on standard NIV interfaces, including helmet NIV, there were $30-50 \%$ of NIV intolerance incidences occurred and $12-33 \%$ of NIV failure due to patients' discomfort despite the best effort demonstrated by skilled caregivers. Beckl (2021), in his study on patients' experience on helmet NIV, revealed that the patient tolerated the helmet well and did not complain of any discomfort. Ngandu et al. (2016) attributed the experience of being on the NIV as unexpected and stressful, while Schmidt et al. (2016) shared $34 \%$ of patients reported regrets at having NIV. Surprisingly, $32 \%$ of those patients had previous experience with NIV. Considering this evidence, helmet NIV alone, without comparing to the other interfaces, still provides comfort in multiple perspectives.

Other examples which illustrate comfort detractors of helmet NIV are; patient-ventilator asynchrony (PVA) (Ghosh \& Elliott, 2017; Olivieri et al., 2016), interface-related complications (Grieco et al., 2021; Patel et al., 2016), claustrophobia (Liu et al., 2020; Schmidt et al., 2016), noise (Pisani et al., 2015; Tiru et al., 2017), humidity and temperature issues (Tiru et al., 2017; Ueta et al., 2012) which indirectly germinate the feeling of fear and anxiety (Ngandu et al., 2016) among patients and contribute to the incident of NIV intolerance and failure. Considering the above-mentioned multi-faceted comfort impeding factors, a strategy to measure patients' level of comfort is needed, and one of the ways is to evaluate their expressed behaviour. Therefore, this study aims to measure the comfort behaviour level of the patient treated with helmet NIV therapy.

\subsection{Literature Review}

\subsection{Issues and Challenges Related to Helmet NIV}

The ability of helmet NIV in providing comfort to patients is superior to other NIV interfaces. However, helmet NIV intolerance and failure are typical responses reported, which indirectly implies the ground of helmet NIV's actual performance. Therefore, the entire discussion on the elements that impede patients' comfort during helmet NIV is presented as follows:

\section{PVA}

PVA is historically known as the most common comfort detractor in helmet NIV therapy. Asynchrony index (AI) reported more than $10 \%$ in $43 \%$ of patients receiving NIV (as cited in Ghosh \& Elliott, 2017). This inharmonious event of the patient's spontaneous breathing activity and ventilator parameters can increase WOB, discomfort, prolonged ventilation therapy, NIV failure, and mortality rate. As Costa et al. (2008) comparative evaluation study on the physical characteristics of different helmets conclude, the larger inner volume and the highly compliant material are significant contributors to PVA. These helmet characteristics allow initial pressure dissipation and the time lag between the inspiratory effort and trigger initiation. Despite plenty of initiatives and inventions made to overcome the issues, this comfort detractor remains a significant challenge due to its subtle appearance that posts difficulty for early recognition (Ghosh \& Elliott, 2017).

\section{Interface related complications}

The interface pressure ulcer commonly occurs at the armpits where the straps are placed (Lucchini et al., 2020) and at the neck area where the helmet seal is located (Patel et al., 2016). Patel et al. (2016) investigated the development of interface-related skin ulcers between helmet and face mask, found no significant difference between the two. Parallel to this, Lucchini et al. (2020) report the application of axillary straps increases the pain score by 4.8 points on the pain scale with the stress detector of 0.206 micro Siemens after 5 minutes of application.

\section{Humidity-Temperature}

The use of heated humidified air during helmet NIV therapy mimics the normal spontaneous breathing processes, which is essential to prevent oral and nasal mucosal dryness (Coppadoro et al., 2021). However, in Dimech (2012), patients likened the environment inside the heated humidified air employed helmet as 'sitting in a sauna with no breeze or anything on the face', which is rather oppressive. The same expression is shared in another study, as patients complain of feeling feverish when the humidifier heater is set at $37^{\circ} \mathrm{C}($ Ueta et al., 2012). In the latest study, the discontent persists as healthy volunteered subjects rate in-helmet environment as $7.4+1.9$ on Visual Analogue Scale (VAS) compared to 8.2+1.9 with mask (Tiru et al., 2017).

\section{Noise}

Since the helmet NIV encloses the patient's entire head during therapy, the patient exposes to tympanic membranes injury from exerted positive pressure (Lucchini et al., 2020). This is proven by Tiru et al. (2017) in their study on healthy volunteers, where the subjects rate the VAS score of ear pressure higher in the helmet $(6.6+1.8)$ than with mask (8.6+1.1). In another controlled laboratory test, (Hernandez et al., 2021) found the noise level is significantly affected by types of NIV interfaces. For example, the noise inside the helmet consistently exceeds $100 \mathrm{~dB}$, higher than the sound intensity during application of facial or nasal mask (barely exceeding $60 \mathrm{~dB}$ ) and ICU background (which range between 55 and $65 \mathrm{~dB}$ ) (Hernandez et al., 2021). The finding is supported by Pisani et al. (2015), as their trial found a total of $10.2 \%$ of patients treated with helmet NIV complain of noise compared to none in the mask group.

\section{Fear}

According to Ngandu et al. (2016), fear is the most recurrent theme in studies concerning patients' experiences undergoing NIV treatment. This unpleasant feeling, which is described as anxiety, is related to various factors. Claustrophobia, a fear of being closed in a confined area, is the most commonly reported factor that leads to the unpleasant experience among helmet NIV users. In Pisani et al. (2015), trial 
on hypercapnia patients, claustrophobia is the main reason for interface change among helmet NIV group, although the incidence is low. The finding is supported by Cortegiani et al. (2019) in the study, as some patients describe their feeling during the therapy as being 'in unbearable times, entrapped, constrained, totally enclosed, locked in somewhere, restricted with no chance to escape, all tied up and suffocated'. Although all patients manage to complete the treatment successfully, some of them feel that they 'couldn't get out of it quick enough, 'almost fighting to be released' and some even state that they would not like to encounter that experience again (Dimech, 2012). The expression synchronises to the finding by Schmidt et al. (2016), as 34\% of patients regret having received NIV over having simple oxygen therapy or intubation. Apart from it, long-term experience using helmet NIV may also contribute to claustrophobia (Pisani et al., 2015).

\subsection{Kolcaba's Comfort Theory}

Kolcaba (1994) defined comfort as "the satisfaction of basic human needs for relief, ease, or transcendence that arise from stressful health care situations". It is developed based on three technical senses of comfort for nursing; relief, ease and transcendence (Kolcaba,1991). Relief in this perspective is defined as the state of assuagement following the fulfilment of the needs (Kolcaba, 1994). Ease is defined as the state of satisfaction or calm (Kolcaba, 1991), whereas transcendence is a state of surpassing beyond the usual limit (pain or problems threshold) (Kolcaba, 1991). Transcendence is the critical stage in comfort senses as the management has successfully provided the required comfort measures (March \& McCormack, 2009).

Next, there are four contexts of experience for the above senses to occur: physical, psycho-spiritual, environmental, and sociocultural (Kolcaba, 1991). In this theory, physical context pertains to the needs derived from physical (e.g., dyspnoea) and physiological (which the appearance is more subtle, e.g., poor oxygenation) dimensions of an individual. At the same time, the psycho-spiritual context concerns internal consciousness of self, including motivation, trust, self-worth and one's relationship to a higher being (Kolcaba, 1991). Unfortunately, those needs are often neglected, especially in emergencies, and can only be pleased by comfort food for the soul, such as therapeutic touch and spending time (Wilson \& Kolcaba, 2004). Next, the environmental context refers to the external aspect of human experiences such as temperature, sound and safety. While the sociocultural context is about interpersonal, family and societal relationships, including family traditions, rituals and religious practices (Kolcaba, 1991).

\subsection{Comfort Behavioural Level of ARF Patients with Helmet NIV}

The existing studies on helmet NIV addressed a broad range of comfort issues encompassing various aspects. Perceived comfort was frequently examined, usually through Visual Analogue Scale (VAS) as one of the predictors in ascertaining the dominating factors that may promote the endurance and tolerance of ARF patients in successfully completing the therapy. However, these studies focus only on the physical variables without providing equal opportunity to the other variables such as, psychological, social and environmental, which warrants the use of more holistic tool to determine overall predicted comfort value among helmet NIV recipients. Thus, it is relevant to extend the existing literature by providing evidence on comfort experience based on behavioural expression in relation to this therapy, which is also supported by Cortegiani et al. (2019) and Bambi et al. (2017). Furthermore, Breivika (2017) highlights that VAS is unreliable for outcome measure in chronic condition as patients tend to have great difficulties making an average score for comfort during a past period. Therefore, the assessment on the global expression of patients are needed for accuracy (Breivika, 2017). The Comfort Behavioural Checklist ( $\mathrm{CBC}$ ) selection is based on the Kolcaba's standing that comfort needs are multi-faceted yet holistic and inter-related, which are better understood when health care provider identify and classify those needs systematically (Wilson \& Kolcaba, 2004). CBC is developed to assist health care provider in identifying those needs via external behaviour expressed by the patients (Kolcaba, 2010). Therefore, it allows data retrieval from patients who are unable to provide verbal information (Kolcaba \& DiMarco, 2005) such as patients who are in acute, grave condition (Kolcaba, 2010) as the patients in this study.

\subsection{Methodology}

There are two types of helmet NIV modes available: Continuous Positive Airway Pressure (CPAP) and Bi-level Positive Airway Pressure (BiPAP) which are used for different indication. Given to the higher frequency usage of helmet CPAP, and the quantity available (the ratio of CPAP versus BiPAP is 4 to 1 ) in the selected research setting, hence this paper focuses on patients treated with helmet CPAP. Therefore, the term helmet NIV in this writing is referring to helmet CPAP. The helmet NIV used in this study is the StarMed Castar helmet CPAP (refer figure 1).


Fig. 1: Application of Helmet NIV 
A cross-sectional quantitative, descriptive, observational study was conducted on ARF patients who completed helmet NIV therapy. The participants were purposively selected from the Emergency and Trauma Department in Perak state tertiary hospital. The sample size was calculated using $G^{*}$ Power Software 3.1.9.2, with the effect size of 0.3 , a standard alpha value of 0.05 and a power of 0.80 . After 15 minutes completion of therapy and confirmed hemodynamically stable, patients' external behaviour was observed and measured using CBC, which consists of five domains: vocalization, motor sign, performance, facial and miscellaneous (Kolcaba, 2010). There are 16 negatively worded items in the CBC: item number 2, 3, 5, 7, 8, 9, 11, 12, 13, 19, 20, 21, 22, 24, 25 and 27, which were recoded accordingly prior to data analysis. The total score of the CBC is 120 , with four cut-offs (refer table 1). The data were analysed using Statistical Package for the Social Science (SPPS) version 22. Ethical approval was granted from the university and Medical Research and Ethics Committee.

\begin{tabular}{ll}
\multicolumn{2}{c}{ Table1: Table of CBC cut-off } \\
\hline Level of Comfort & Scoring \\
\hline Not Comfortable & $0-30$ \\
Somewhat Comfort & $31-60$ \\
Moderate Level of Comfort & $61-90$ \\
Strong Level of Comfort & $91-120$ \\
\hline \multicolumn{2}{c}{ (Source:Kolcaba, 2010) }
\end{tabular}

\subsection{Findings}

\subsection{Participants' Profile}

The sample consists of 67 participants, with age ranging between 30 and 88 years old, mean age of 65.03 , standard deviation (SD) 12.43. There were $64.2 \%$ male and $35.8 \%$ female. Malay contributed to the largest percentage of participants, followed by Indian, Chinese and other with $41.8 \%, 32.8 \%, 23.9 \%$ and $1.5 \%$, respectively. $52.2 \%$ of patients were treated for Acute Pulmonary Oedema (APO) and the remaining were non-APO (47.8\%). Table 2 summarizes the participants' profile of this study.

Table 2: The Profile of Participants ( $\mathrm{N}=67)$

\begin{tabular}{lcccc}
\hline Variable & Frequency $(\mathrm{N}=67)$ & Percentage $(\%)$ & Mean & Standard Deviation (SD) \\
\hline Age & & & 65.03 & 12.43 \\
Gender: & 43 & 64.2 & & \\
Male & 24 & 35.8 & & \\
Female & & & \\
Race: & 28 & 41.8 & \\
Malay & 16 & 23.9 & \\
Chinese & 22 & 32.8 & \\
Indian & 1 & 1.5 & \\
Others & & & \\
Diagnosis & 35 & 52.2 & \\
APO & 32 & 47.8 & \\
Non-APO & & & \\
\hline
\end{tabular}

\subsection{Comfort Behavioural Level of ARF Patients with Helmet NIV}

The mean score of CBC was 88.54, SD 7.35 which indicates moderate in comfort after completion of helmet therapy. The analysis of mean of the comfort score based on the participants' diagnosis also revealed the same pattern, with the mean of comfort score for participants with APO was $89.88, S D 7.25$ whereas for non-APO was $87.08, S D 7.80$. The details are presented in table 2 .

Table 3: Comfort Behavioural Level Based on CBC

\begin{tabular}{lccc}
\hline \multirow{2}{*}{ Comfort Behavioural Level } & \multicolumn{2}{c}{ Diagnosis } & \multirow{2}{*}{ Total } \\
\cline { 2 - 3 } & APO & Non-APO & \\
\hline Comfort Score, mean (SD) & $89.88(7.25)$ & $87.08(7.08)$ & $88.54(7.35)$ \\
Comfort Level: & & & \\
Strong Level of Comfort (\%) & $17(25.40)$ & $11(16.40)$ & $28(41.79)$ \\
Moderate Level of Comfort (\%) & $18(26.90)$ & $21(31.30)$ & $39(59.21)$ \\
Somewhat Comfort (\%) & $0(0)$ & $0(0)$ & $0(0)$ \\
Not Comfortable (\%) & $0(0)$ & $0(0)$ & $0(0)$ \\
\hline
\end{tabular}

\subsection{Discussion}

The descriptive analysis was done to assess the comfort behavioural level of ARF patients in relation to helmet NIV therapy according to CBC scores. The findings indicate that the comfort level of patients is moderate with the mean score of $88.54, S D 7.35$. This finding reflects that the helmet NIV can be considered as comfortable NIV interface for ventilatory support therapy as reported by previous studies (Lucchini et al., 2020; Olivieri et al., 2016; Patel et al., 2016; Tiru et al., 2017).

Since comfort is an outcome of/from multiple aspects, as emphasized in Kolcaba's Comfort Theory, it is not surprising that CBC scores are only within the range of moderate level of comfort. This is congruent with the study by Tiru et al. (2017), who found similar results for 
overall comfort level. They also reported different elements: inspiration and expiration triggering, claustrophobia, noise, temperature and eye pressure produce different VAS scores, further weighted the multi-faceted characteristic of comfort. Besides, other studies also specify other comfort influencing factors such as PVA (Olivieri et al., 2016), interface related skin ulcer (Patel et al., 2016) and claustrophobia (Pisani et al., 2015). Hence, this indirectly implies that there are elements related to helmet NIV which able to influence the total comfort. The low number of participants $(41.88 \%)$ who rate their comfort level as most comfortable and the high number of participants $(58.20 \%)$ who rate their comfort level as moderate comfort further strengthens the conjecture. Dimech (2012) in his phenomenological study on patients' experience on NIV helmet, prove that each individual responds differently; ranging from reluctantly to willingly accepting the therapy, though the participants manage to complete the treatment. This is in congruent with the findings of a thematic synthesis by Ngandu et al. (2016) which attribute the experience of being on the NIV as unexpected.

\subsection{Conclusion \& Recommendation}

This research provides important implications for both theory and practice. Since attempts to understand ARF patients' behaviour in response to helmet NIV is scarce; this research is perhaps one of the first few attempts to address such limitations. Accordingly, the findings enrich the understanding on patients' genuine response toward therapy which is significant in development of better quality of care. To the researcher's knowledge, this is the first study conducted in Malaysia to understand the behaviour expressed by ARF patients on helmet NIV. The main limitation of this study is recruiting challenges as this study was conducted in one centre and sample was taken purposively among ARF patients, who receive helmet CPAP treatment. Though this sampling is reasonable to ensure representativeness of the population but the generalizability of the finding may be limited. Hence, the results of this research cannot necessarily be generalized beyond the population studied. As to confirm the generalizability of the research finding to other settings, replication of this research is required. Future research may want to employ probability sampling method and examine the proposed framework across different contexts, particularly different samples and helmet mode (BiPAP). A survey that concerns on specific factors that impede the comfort state during helmet NIV therapy is also needed, thus providing the opportunity to understand further on those identified factors and ease the effort of therapy improvement. Future research to explore the comfort level among different races would be helpful since Malaysia has a multi-race population.

\section{Acknowledgements}

Thank you, Allah for giving us this opportunity to complete this research. We would like to express our gratitude to the Malaysia Ministry of Health and UiTM for giving the permission to conduct this study.

\section{Paper Contribution to Related Field of Study}

The result of this study perhaps could be used to enhance the Helmet Therapy patient management and care of comfort among nurses and the multidisciplinary healthcare team.

\section{References}

Bambi, S., Mati, E., Felippis, C. De, \& Lucchini, A. (2017). Non-invasive ventilation:open issues for nursing research. Acta BioMed For Health Professions, 88(1), 32-39. https://doi.org/10.23750/abm.v88i1-S.6282

Breivika, H. (2017). Fifty years on the Visual Analogue Scale (VAS) for pain-intensity is still good for acute pain. But multidimensional assessment is needed for chronic pain. Scandinavian Journal of Pain, 11(1), 150-152. https://doi.org/10.1016/j.sjpain.2016.02.004

Coppadoro, A., Zago, E., Pavan, F., Foti, G., \& Bellani, G. (2021). The use of head helmets to deliver non-invasive ventilatory support: A comprehensive review of Technical Aspects and clinical findings. Critical Care, 25(1). https://doi.org/10.1186/s13054-021-03746-8

Cortegiani, A., Navalesi, P., Accurso, G., Sabella, I., Misseri, G., Ippolito, M., Bruni, A., Garofalo, E., Palmeri, C., \& Gregoretti, C. (2019). Tidal volume estimation during helmet non-invasive ventilation: An experimental feasibility study. Scientific Reports, 9(1). https://doi.org/10.1038/s41598-019-54020-5

Dimech, A. (2012). Critical care patients' experience of the helmet continuous positive airway pressure. Nursing in Critical Care, 17(1), 36-43. https://doi.org/10.1111/j.14785153.2011.00478.x

Ghosh, D., \& Elliott, M. W. (2017). Looking under the bonnet of patient-ventilator asynchrony during non-invasive ventilation: does it add value? ERJ Open Research, 3(4), 00136-02017. https://doi.org/10.1183/23120541.00136-2017

Grieco, D. L., Menga, L. S., Cesarano, M., Rosà, T., Spadaro, S., Bitondo, M. M., Montomoli, J., Falò, G., Tonetti, T., Cutuli, S. L., Pintaudi, G., Tanzarella, E. S.,

Piervincenzi, E., Bongiovanni, F., Dell'Anna, A. M., Delle Cese, L., Berardi, C., Carelli, S., Bocci, M. G., ... Zaccone, C. (2021). Effect of helmet non-invasive ventilation vs high-flow nasal oxygen on days free of respiratory support in patients with COVID-19 and moderate to severe hypoxemic respiratory failure. JAMA, 325(17), 1731-1743. https://doi.org/10.1001/jama.2021.4682

Grieco, D. L., Menga, L. S., Raggi, V., Bongiovanni, F., Anzellotti, G. M., Tanzarella, E. S., Bocci, M. G., Mercurio, G., Dell'Anna, A. M., Eleuteri, D., Bello, G., Maviglia, R., Conti, G., Maggiore, S. M., \& Antonelli, M. (2020). Physiological comparison of high-flow nasal cannula and helmet non-invasive ventilation in acute hypoxemic respirator 
failure. American Journal of Respiratory and Critical Care Medicine, 201(3), 303-312. https://doi.org/10.1164/rccm.201904-0841oc

Hernández-Molina, R., Fernández-Zacarías, F., Benavente-Fernández, I., Jiménez-Gómez, G., \& Lubián-López, S. (2017). Effect of filters on the noise generated by continuous positive airway pressure delivered via a helmet. Noise \& health, 19(86), 20.

Liu, Q., Shan, M., Zhu, H., Cao, J., \& Chen, R. (2020). Non-invasive ventilation with a helmet in patients with acute respiratory failure caused by chest trauma: A randomized controlled trial. Scientific Reports, 10(1). https://doi.org/10.1038/s41598-020-78607-5

Lucchini, A., Bambi, S., Gurini, S., Di Francesco, E., Pace, L., Rona, R., ... \& Elli, S. (2020). Noise Level and Comfort in Healthy Subjects Undergoing High-Flow Helmet Continuous Positive Airway Pressure. Dimensions of Critical Care Nursing, 39(4), 194-202.

Kolcaba, C. (2010). Comfort Questionnaires. Comfort Line. www.TheComfortLine.com

Kolcaba, K. Y. (1991). A Taxonomic Structure for the Concept Comfort. Image: The Journal of Nursing Scholarship, 23(4), 237-240. https://doi.org/10.1111/j.15475069.1991.tb00678.x

Kolcaba, K. Y. (1994). A theory of holistic comfort for nursing. Journal of Advanced Nursing, 19(6), 1178-1184. https://doi.org/10.1111/j.1365-2648.1994.tb01202.x

Mohammed, K., Nolan, M. B., Rajjo, T., Shah, N. D., Prokop, L. J., Varkey, P., \& Murad, M. H. (2016). Creating a Patient-Centered Health Care Delivery System. American Journal of Medical Quality, 31(1), 12-21. https://doi.org/10.1177/1062860614545124

Ngandu, H., Gale, N., \& Hopkinson, J. B. (2016). Experiences of non-invasive ventilation in adults with hypercapnic respiratory failure: a review of evidence. European Respiratory Review, 25(142), 451-471. https://doi.org/10.1183/16000617.0002-2016

Olivieri, C., Longhini, F., Cena, T., Cammarota, G., Vaschetto, R., Messina, A., Berni, P., Magnani, C., Della Corte, F., \& Navalesi, P. (2016). New versus Conventional Helmet for Delivering Non-invasive Ventilation. Anesthesiology, 124(1), 101-108. https://doi.org/10.1097/ALN.0000000000000910

Patel, B. K., Wolfe, K. S., Pohlman, A. S., Hall, J. B., \& Kress, J. P. (2016). Effect of Non-invasive Ventilation Delivered by Helmet vs Face Mask on the Rate of Endotracheal Intubation in Patients With Acute Respiratory Distress Syndrome. JAMA, 315(22), 2435. https://doi.org/10.1001/jama.2016.6338

Pisani, L., Mega, C., Vaschetto, R., Bellone, A., Scala, R., Cosentini, R., Musti, M., Del Forno, M., Grassi, M., Fasano, L., Navalesi, P., \& Nava, S. (2015). Oronasal mask versus helmet in acute hypercapnic respiratory failure. European Respiratory Journal, 45(3), 691-699. https://doi.org/10.1183/09031936.00053814

Schmidt, M., Boutmy-Deslandes, E., Perbet, S., Mongardon, N., Dres, M., Razazi, K., Guerot, E., Terzi, N., Andrivet, P., Alves, M., Sonneville, R., Cracco, C., Peigne, V., Collet, F., Sztrymf, B., Rafat, C., Reuter, D., Fabre, X., Labbe, V., ... Demoule, A. (2016). Differential Perceptions of Non-invasive Ventilation in Intensive Care among Medical Caregivers, Patients, and Their Relatives. Anesthesiology, 124(6), 1347-1359. https://doi.org/10.1097/ALN.0000000000001124

Tiru, B., Stefan, M., Tidswell, M., Lutfy-Clayton, L., Frechette, C., Steingrub, J., \& Hill, N. (2017). Tolerance of the Helmet Interface for Non-invasive Ventilation in Normal Persons. Chest, 152(4), A395. https://doi.org/10.1016/j.chest.2017.08.421 